\title{
Semiotic Analysis of Video COVID-19 by World Health Organization
}

\author{
Vista Octarensa \\ Communication Department, BINUS Graduate Program, \\ Master of Strategic Marketing Communication, Bina \\ Nusantara University, Jakarta, Indonesia 11480.
}

\begin{abstract}
Purpose: This research discusses the semiotic social analysis in a video titled "COVID-19" released by the World Health Organization. COVID-19 is a virus that has become a global pandemic. Very rapid spread makes the WHO issued recommendations to minimize outside activities in the form of social campaigns against the community. World Health Organization released a video titled "COVID-19" on the official youtube channel. The research approach: using a semiotic analysis method with the constructivist paradigm. Semiotic is a sign of science that has consisted of two elements, Signifier and Signified. In a social campaign video, it has a distinct meaning of communication. In this study, semiotics will explain the meaning of visual communication in videos released by the World Health Organization. The results of the study: indicate that semiotic analysis can reveal the signification meaning of the sign in the video campaign. World Health Organization can emphasize the word StayIn and convince people to continue to do social distancing. The World Health Organization explains that by doing five acts, everyone can be heroic against the pandemic. The five acts can be done by hiding in-home, laying down, playing games, staring on anythings. Simple acts can bring a significant impact to all.
\end{abstract}

Keywords:- Semiotic, Signification, World Health Organization, Covid-19, Social Campaign.

\section{INTRODUCTION}

This Youtube is a social media that is used by various groups to carry out promotions, upload music videos, educational videos, videos about activities to educational campaigns and corporate social responsibility companies, organizations and even personal media. Youtube can be accessed and anytime and anywhere. With videos uploaded on Youtube, many people can access without limitations. Youtube is very popular and fond of many people in various countries. Youtube has become the latest trend for many large companies and organizations. In a company and organization, Social Campaign and Corporate Social Responsibility are things that often occur, companies and organizations must run and help governments and even the world to educate and make a positive impact on the environment, regions, countries and even the world. Corporate Social Responsibility is strategies for the company to survival and growth; emphasize the corporate brand value (Lee, 2019).

\author{
Muhammad Aras \\ Communication Department, BINUS Graduate Program, \\ Master of Strategic Marketing Communication, Bina \\ Nusantara University, Jakarta, Indonesia 11480.
}

Social campaigns can be run in various ways, by going to the field, providing financial assistance, providing environmental counselling, free advertising on social media. In conveying social campaigns can be through various ways both directly and using the media. The company uses YouTube as one of the media to carry out social campaigns. Social campaigns through videos that educate and support positive impacts. The video can then be uploaded and distributed via the company's website, YouTube, Instagram and other social media. Another goal of social campaigns is to change behaviour and motivate the community. In 2019, a virus that appears in Wuhan, China disrupted in various countries began to occur. In 2020, the virus has become a global problem and has had an enormous impact on various countries. This, because the virus began to spread and attack many countries in the world. Coronavirus, which is similar to SARS, Ebola and MERS, is named as Covid-19. Spread is very fast and is a problem in many parts of the world. Viruses that spread with a short touch can cause infection of the respiratory tract in humans. Generally, the symptoms of COVID-19 are fever, fatigue, dry cough, shortness of breath, pain, sore throat. COVID-19, which is a global problem, is monitored directly by the World Health Organization.

The World Health Organization is a specialized agency of the United Nations responsible for international public health. The main objective as ensuring the attainment by all peoples of the highest possible level of health. World Health Organization established in 1948, which commemorated as World Health Day. World Health Organization is a broad mandate including advocating universal healthcare, monitoring health risks, coordinating responses to health emergencies, and promoting human health and well being in the world. World Health Organization (WHO) during this challenging time, created a playlist titled coronavirus on WHO official YouTube account. In the playlist, there are several videos, starting from the origin of COVID-19, the types of viruses, how to prevent COVID-19, updates on COVID-19 cases, to social video campaigns that motivate people in the world to keep Stay In. The pandemic period, which was a result of COVID-19 made many countries hold restrictions on human interaction, to lockdown. Happens because the limitation of interaction is a way to break the distribution chain of COVID-19. Minimize the number of people affected by the virus. WHO encourages people to stay at home and minimize going out. One of the videos titled "Covid-19" which depicts support to the community is 
facing the pandemic and keep Stay In. WHO in the video explained that Stay in can save humankind in this world.

The social campaign is one of Public Relations activity. In the 1 minute video, can provide motivation and support to all people in the world. WHO understands that limiting interactions is very difficult for every social community in the world to do. Nevertheless, this must manage by every human being. The video titled COVID-19 has campaign, communication, social, psychological, environmental and cultural value in it. A video contains visual elements languages. In the delivery of visual languages, there are semiotic social values in it. Social semiotic can contribute to social change (Engebretsen \& Kennedy, 2020, p. 51). Semiotics is commonly known as the study of signs and sign systems. In this study, researchers will conduct a semiotic social analysis on a video titled COVID-19 by WHO. So, to understand the meaning of messages and visual languages conveyed by WHO to the public, add insight and references for other researchers, adding knowledge about the meaning of denotation, connotation and myth in semiotics, especially in the field of communication. Furthermore, this research can be a reference for other social campaign video makers with the creation and delivery of messages that are good, right and directed.

\section{LITERATUR REVIEW}

\section{A. Pandemic coronavirus}

Pandemic is traditionally applied to epidemics that occur worldwide, crossing international boundaries and affecting many people (Hirsch \& Duval, 2013). Coronavirus disease (COVID-19) pandemic is an infectious disease caused by a newly discovered coronavirus. Most people infected with the COVID-19 virus will experience mild to moderate respiratory illness and recover without requiring special treatment. Older people and those with underlying medical problems like cardiovascular disease, diabetes, chronic respiratory disease, and cancer are more likely to develop severe illness. WHO suggests that people must take social distance during the pandemic outbreak (WHO, 2020). The social distance used to increase intimacy among people (Song \& Kang, 2015).

\section{B. Semiotics}

Semiotics, the theory of signs, sprang in its modern form from the 17th-century empiricist philosopher John Locke, who theorized that words stand for ideas in each person's mind and that communication fails when people use words with different or unclear meanings. Under the influence of seminal thinkers such as Charles S. Peirce and Ferdinand de Saussure, sophisticated theories were developed in the 20th century to explain types and systems of signs and how signs function in mind and society (Craig, 2016).

Semiotics is the study of Signs and signs system. Signs are building blocks of semiotics. Sign systems know as Code, Code usually includes language, gestures, objects, music. In real life, sign not stand alone, the code must be understood in terms of mutual influences. Semiotics analyzes virtually any part of the communication field. A semiotic analysis typically examines how some particular text, like words, images, movies, songs, ads. Any kind used to construct what sort of meanings in communication. Semiotics analysis as a tool to examine the misunderstandings of frequent communication (Littlejohn, Stephen, \& Foss, 2009).

Semiotics is related to all aspects of human activity. Semiotic defined as the innate capacity for sign compression, representation labels the mind's ability to use signs to refer to the world and other signs, and signifying order denotes the collective sign system of a culture. The signifying order thus provides the means for developing human beings to organize the raw information that is comparable to the world is not a direct one. It mediated by signs and thus by referential domains that they are within mind space. Semiotic is the processual chaining of interpreters and representation as the most general "standing for" or "substitutionally" relationship between sign and object are both mentioned. Semiotic analysis is until documenting and conducting studies in the structure (Parmentier, 2016).

Social semiotics is a deepening of the theory of semiotics, in social semiotics consider language and sign making widely and is the key to the reproduction or transformation of social structures. Social semiotics emphasizes "how people make their mark in a context of interpersonal and institutional power relations to achieve specific goals". Social semiotics also discusses language, and other ways of communication, especially visuals, working together to form a meaning (Engebretsen \& Kennedy, 2020). Semiotics also a linguistic-based theoretical and analytical tool, to explore an alternative perspective for evaluating the quality and reliability of sustainability reports for CSR communication, Social campaigns, etc (Yekini, Omoteso, \& Adegbite, 2019).

In visual communication, semiotics based on the assumption that almost anything can be a sign or symbol, which means that it stands for and raises in the minds of the audience an object, person, or concept separate from the sign itself. Even visual phenomena that occur naturally, without communicative intent, can be interpreted as a sign. Roland Barthes distinguishes between image denotations and their connotations.

The denotation of an image is only the contents of the image. Connotation, on the other hand, includes all the values and emotions that might be triggered by images in the viewer. (Littlejohn, Stephen, \& Foss, 2009). Denotation is the level of descriptive and literal meaning agreed upon by all members of a culture. At the level of connotation, the meaning produced by the relationship between signifiers and broad culture, which includes beliefs, behaviour, frameworks, and ideology of social formation. Barthes's semiology in basic terms wants to learn how humans use things; it makes sense (signifying) that this cannot equate with communication. Meaning means that the object that 
wants to communicate is still a structured sign system (Irawan, 2019). Institutionalization of denotation requires the doubling of references, markers, and signified, connotational institutionalization involves decoupling among the three (Li, 2017).

\section{Social Campaign}

A campaign can build emotional sympathy and greatest impact (Park \& Cho, 2020). Social campaigning is the field which is a type of non-profit marketing, which includes public health campaigns (e.g., those to reduce smoking, alcoholism, drug abuse, overeating); environmental campaigns (e.g., wilderness protection, recycling) and other campaigns (e.g., human rights, social equality) ( Sharma, Bhosle, \& Chaudhary, 2012). The campaign has a powerful impact that leads to countless actions (Corndana, Johson, \& Kenney, 2015). Mass Media campaigns are a means of promoting awareness and emphasizing behaviour change; meaningful populationlevel changes can create with small effect in a large group of individual. Have been implemented concurrently with appropriate resources have shown positive effects (Heather, 2016).

\section{Sign}

A sign is the core concept of semiotics. A sign is when one thing stands for another thing. A sign is a relationship. It is the linking of two different things so that one can stand for the other. Ferdinand de Saussure developed a sign, has consisted of two elements. A signified (is a thing - an object, a concept, an emotion) and a signifier ( is an arbitrary symbol that has chosen to stand for thing). Linkage of signifier to signified is a matter of convention, not a necessity (Upton, 2015).

A sign is anything that stands for something else. A sign stands for an object or concept. The signified is the form in which it stands (content) called the signified. The signifier is the form in which the content was express, the world, sound, picture, or gesture. Saussure notes that both visual and verbal communication equally represented as a signifier (Barbatsis, Kenney, \& Smith, 2005).

The linguistic sign has two aspects which are inseparably connected: the sound sequence (signifier) and the concept (signified). This structure, corresponding relation between sound and meaning is apparent and specific. However, the fixed corresponding relations will be split apart deliberately by rhetors in rhetorical activities. The original meanings are accordingly changed, and new meanings would be created, which produce unexpected impacts on language expression. After the corresponding relation between "signifier" and "signified" is set apart, the change of meaning will take different forms (Ying, 2019).

The sign consists of two parts: the signifier and the signified. The first refers to sound patterns that are not material sounds, purely physical things, but the psychological imprints of sound, the impression they make on our senses; the latter refers to concepts or thoughts, which are more general and abstract. Saussure points out two fundamental principles of linguistic signs: (1). Arbitrary is nature of the sign; (2) The linear nature of the signifier. A sign has two parts, and that makes arbitrary relationships between them. Language can make any connection between them. Based on this fundamental property, the signs are also characteristic of mutability. Over time, the language and signs change. New signifiersignified links may replace old ones or increase the amount (Shumin, 2019). Signifiers can signify more than one culture dimension (Zahedi \& Bansal, 2011).

Saussure formulated the well know postulate that signifier and signified are connected arbitrarily in language. Between the word table and the object, there is no identity or even similarity. It can be understood as the possibilistic aspect of meaning. The word table signifies something that could be signified differently, which is a case in other languages; the different country has a different language (Epstein, 2019).

They distinguished by the type of relationship between the signifier and signified. An icon has a relationship of similarity (a photograph is an icon because it usually looks like the person or object depicted). An index has a relationship of contiguity or connection; thus an index points to what it stands for (if their wedding cake topper is saved by the couple eat on their anniversary, that is an index because it was initially part of the wedding cake and only conveys meaning as a result of that connection). A symbol has a relationship of arbitrariness (that the word cat has no whiskers, as Gregory Bateson famously noted, means it is a symbol) (Littlejohn, Stephen, \& Foss, 2009).

Through Ferdinand de Saussure's theory, it can examine the semiotic aspects of the COVID-19 social campaign video released by WHO. Semiotics can learn the signs that are in the short video. Through visual and audio communication, they deliver profound messages about the pandemic so that the video can be adequately understood and conveyed more optimally to the public to care more and be together to fight the pandemic.

\section{RESEARCH METHOD}

This study uses a constructivist paradigm; this study looks at the reality of what appears in the COVID-19 video. Paradigm is a way of looking at people and themselves. The paradigm is related to assumptions and beliefs that are considered correct that can influence the practices that are applied (Sanjaya \& Budimanjaya, 2017). Paradigm is a view to understanding the real world. (Mulyana \& Deddy, 2003). Constructivism research studies the reality constructed by individuals and the implications of that construction for their lives with others. In constructivists, each individual has different experiences. Thus, this research strategy suggests that every way individuals take to view the world is valid, and the need for mutual respect for these different views (Patton \& Quinn, 2002). 
In this study, researchers used a qualitative approach. A qualitative approach is an approach or tracker to explore and understand a central phenomenon. The qualitative approach is examined through data in the form of words or text and then analyzed. (Semiawan, 2010). Qualitative research is used in social science research to gather information from participants who have firsthand information about a phenomenon (Ransaw Gause Major, 2019). Qualitative research approaches help to gain insight into the processes involved in co-construction of meaning, lived experience, culture, rituals, and oppressive practices (Atkison, 2017).

Methode used is a semiotic analysis method. In social science, semiotics is a language and other means of communication, especially visuals, which work together to form a meaning. Semiotics studies the nature of the existence of a sign. Semiotic expert, Saussure formulated the well know postulate that significant and signified are connected arbitrarily in language.

This research is about the social video social campaign entitled "COVID-19" released by the World Health Organization (WHO) and published through the official YouTube channel, which lasts for 60 seconds. Identify research objects that have a theme of caring for all people in the world, especially people who are struggling to stay at home and reduce interaction, to minimize the possibility of the spread of the COVID-19 virus. This video also tells how WHO invites all people and gives enthusiasm to people who are doing social distancing. The data of this study were obtained from primary data sources observing the WHO video titled "Covid-19" from the youtube video on the computer. Then the secondary data obtained is used to support the research process. Secondary data used is done through literature studies to obtain information from the literature relating to the title of the study, such as books, journals, websites, related writings and others. Data analysis uses research methods or semiotic methods, also known as semiology analysis. In the semiotic analysis, the writer refers to the 2 scene samples from the video "COVID-19" as follows :

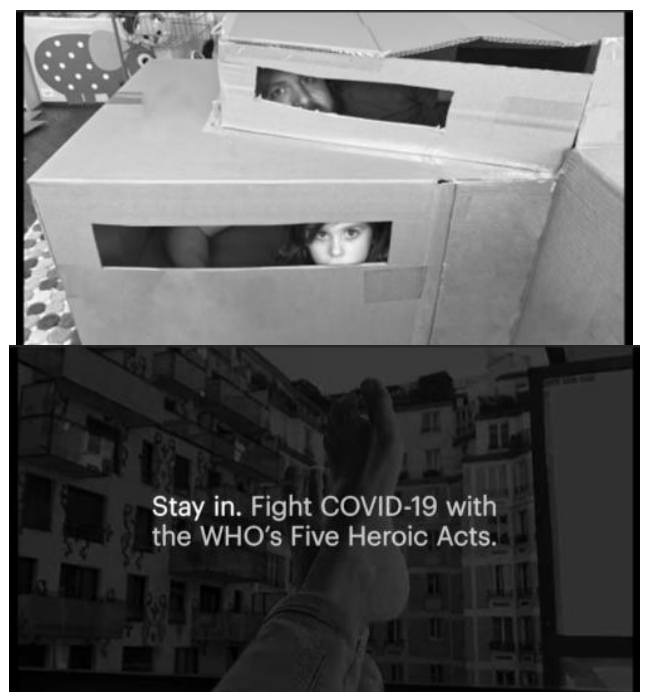

Fig 1

\section{FINDING AND DISCUSSION}

Based on the results of the study, it shows that Social Campaign through the Youtube video COVID-19 by WHO wants to emphasize the issue of Stay In, stay at home to invite all people to participate against a pandemic that is against the world. The analysis results are as follows:

In the first scenes, visible visual as a signifier in the video is a picture of a residential roof with a monochrome display. The signifier shown is a gloomy atmosphere in a housing complex. The signification shown is a mourning atmosphere with a dark colour theme on the video, showing that COVID-19 is becoming a pandemic.

In the second scenes, a visible visual signifier in the video is in a front fence of the house and shops with a monochrome display with a quiet atmosphere. The signifier shown was a gloomy atmosphere with home streets and shops closed. Signification that is displayed is the quiet atmosphere that arises due to social distance in shops and streets that are carried out to fight the COVID-19 pandemic that is happening in the world.

In the third scenes, visually visible as a signifier in the video is a multi-storey building, offices in a large city with a monochrome display with a quiet atmosphere. The signifier shown was a gloomy atmosphere with offices and industries that were quiet from the crowd. Signification that displayed is that many offices and industries have stopped operating, due to the social distance that carried out to fight the COVID-19 pandemic that is happening in the world.

In the fourth scenes, visually visible as a signifier in the video is a picture of an empty Eiffel Tower in Paris with a monochrome display in a quiet atmosphere. The signifier shown is the gloomy atmosphere of the Eiffel tower in the tourist city of Paris. Signification showed, tourist city and iconic place of Paris which usually crowded to be visited, now become quiet and empty due to the pandemic. This happens to fight the COVID-19.

In the fifth scenes, visually visible as a signifier in the video is a young man who looks out the window of the house with a sad face with a monochrome look. Signified shown is the desire of young men to get out of the house and do activities. The signification shown is a sad young man who usually has a social life, hoping to interact outside and travel from home. This is by WHO's expectation that people stay at home and not go out.

In the sixth scenes, the visual appearance as a signifier in the video is a child and adult hiding inside a box with a monochrome display. Signified shown are small children and adult. They have seen both of them hiding in the box with sad eyes and unhappy expressions, showing sadness in hiding inside and hoping to get out of the hiding. Signification that is displayed is hiding is boring, and the thing that wants to do is get out of hiding, a pandemic that occurs makes people have to hide and keep quiet, not go out on a trip, following WHO's recommendations. 
In the seventh scenes, visually visible as the signifier in the video is a woman lying on a chair with a monochrome display. The signified is that a woman is spending time relaxing in the house and staying alone. The signification displayed is at home and spending time in bed, which is one movement that can help fight the COVID-19 pandemic.

In the eighth scenes, visually visible as a signifier in the video is a closed eye with a monochrome display. The signified was that the man slept while staying at home. Signification that is displayed is to do sleep and keep quiet at home, is one way that can help fight the COVID-19 pandemic that occurred. By sleeping and staying silent, it can help reduce direct interaction with others. This is in line with WHO expectations so that all people can sleep and stay indoors.

In the ninth scenes, visually visible as the signifier in the video is a woman wearing sunglasses smiling, with a cake, a birthday hat, and a laptop with a video call with her friends with a monochrome display. Signified shown a woman with glasses is celebrating a birthday and interacts with friends through video calls made through a laptop. Signification that is displayed is a birthday celebration and interact with others can be done via video call without having to meet in person, all celebrations can be done with technological advances, monochrome showed remain in a sad atmosphere in fighting the COVID-19 pandemic that occurred. WHO shows many ways that can be done to interact, technology can bring everyone together, without having to get close.

In the tenth scenes, visually visible as the signifier in the video is a man standing facing the window with a glum face. The signifier displayed is a person looking out the window and feeling bored in the house and eager to get out. Signification that is displayed is being at home is annoying, but it can help fight the COVID-19 pandemic.

In the eleven scenes, visually visible as the signifier in the video is a girl playing with a picture on the floor with a monochrome display. The signifier shown is a girl spending time at home playing alone, without interacting with friends. Signification that is displayed is spending time playing alone; game activities can be done creatively inside the house.

In the thirteenth scene, visually visible as a signifier in the video is a father with a work coat in top clothes and home pants in underclothes, looking at a laptop and apprenticing a toddler under a table with a monochrome display. The signified was that the man was working inside the house and had a meeting with other workers. Signification shown is that although not getting close, going to the office, work activities can still be done through technological advances in the home. Social limitations still allow us to work and move.
In the fourteenth scenes, visually visible as a signifier in the video is an Asian teenage boy sitting on a balcony in a clothesline and using a laptop. Signified shown is by showing Asian male teenagers, doing their work using a laptop on the balcony of the apartment, even though not at university, learning activities can still take place anywhere, both on the balcony of the apartment. Signification that is displayed is even though not getting close and being in the house, tasks and various activities can be done with technological advancements such as laptops that make it easy. Social limitations do not inhibit us and allow us to keep learning.

In the fifteenth scenes, visually visible as a signifier in the video is an Asian grandmother, standing in a medical device and listening to headphones. Signified shown is with Asian grandmothers, doing their own sports activities inside the house while listening to songs. Signification that is displayed is that although not getting close and being at home, exercise can be done alone, without having to interact with others, spending time during the pandemic with healthy activities, following WHO's recommendation not to go out of the house and run social distancing.

In the sixteenth scenes, seen visually as a signifier in the video is a young man who was standing in a balcony using a laptop room. Signified is shown by showing young men, working on their activities through a laptop in the house, without having to travel. Signification that is displayed is even though not getting close and being in the house; various activities can still be done with technological advancements such as laptops that make it easy. Social limitations do not touch us and allow us to keep learning following WHO's recommendation not to go out of the house and run social distancing.

In the seventeenth scene, visually visible as a signifier in the video is a young woman holding a pair of scissors and smoothing her hair and facing the glass with a monochrome look. Signified shown is that a young woman is happy in cutting and smoothing her hair. The signification shown is a small activity that is done outside the home, can be done by herself and gives happiness, the young woman looks happy even though she has to cut her hair and not in the salon-like she does as usual. She can still pass the day with a smile, even though she must be silent and not getting close to others.

In eighteenth scenes, the visual image as the signifier in the video is a father and his two children, with a laptop and a messy table with a monochrome display. The signified is that a father is on the verge of defeat with both of his kids when he has to work while looking after his two children, so he cannot focus on working. The signification shown is that working at home is not easy while keeping children dizzy and hampering work. The signification shown is that working while caring for children is not an easy thing to do. However, this must be done in the current situation; everyone must be able to do that. 
In nineteenth scenes, visually visible as a signifier in the video is a young woman sitting on the floor with barbells, crackers and a laptop. Signified shown is a young woman sitting alone after exercising, doing casual activities by watching through a laptop while eating crackers. Signified which is shown is that the activities at home by exercising themselves to maintain health, to relax by watching and eating snacks, is a fun activity while at home, many activities can be done while alone at home, without the need to interact directly with others. Following WHO recommendations, stimulating activities can still be done at home without having to get near.

In twenty scenes, the visual image as the signifier in the video is a picture of a foot facing an apartment building with the words Stay In. Fight COVID-19 with the WHO's Five Heroic Acts. Signified shown is the feet of someone who lives indoors and is looking at the view of an apartment, a building outside with a relaxed position and the words Stay In, Stay at home which is an appeal from WHO to remain silent at home doing all activities while staying at home, not getting close, the Five Heroic Acts which show that five things everyone can do to save the world from the COVID-19 pandemic. The intended signification is that relaxing at home and doing the Five Heroic Acts that shown earlier namely Hiding in the house, Laying down, Napping, Playing games and staring of anythings are activities that can save humankind by not getting close, by social distribution and Stay In.

In each, there is audio as a significant male voice speaking in a firm voice. Signified shown is the man seriously explain about the video. The signification shown is that WHO expressly provides support and directs the community to stay at home, vocal form and every word issued shows that this is very serious and must be carried out by all parties.

From the various screen, Singnifiction that World Health Organization wants to show something meaningful about this social campaign. World Health Organization wants to invite and encourage everyone in the world even though the activity is very dull and sad, by showing older people, adults, young, kids, Asian scenes, all kind activities, wants to show that everyone from among people, ages, jobs, activities must do the same thing, stay in and help save our world from the COVID-19 pandemic. With a stay at home, which usually people go out to activities, but now they must hiding inside the house, lazing on the mattress, sleeping as much as he could, playing games, and staring to any things, that makes everyone can be a hero. This is in accordance with the goals of the campaign and the focus of WHO itself, which is eliminating COVID-19, breaking the chain of virus spread, reducing the number of people affected by the virus, and restoring this world. Symbols become signs that can be interpreted differently in each individual.

\section{CONCLUSION}

Based on the research findings, the meaning of the message contained in the social video campaign in Youtube World Health Organization entitled "COVID-19", can be concluded as follows: First, that a social campaign video can change the views, thoughts and direct people to make a change for the better. Social media is New Media which has a significant influence on society. Through videos on YouTube, the social campaign "COVID-19", the World Health Organization wants to contribute proactively to the pandemic that occurs and provide direction and encouragement to the community to carry out social distancing and stay in by doing their activities at home and family, without having to travel and interact directly with other people. Relates to public relations activities that want to provide social awareness to the community. Second, through the video "COVID-19", the World Health Organization shows care and appreciates the heroes who force themselves at home even though it is challenging to do. Third, with the background sound of video using a firm male voice and a video with a monochrome concept, showing the seriousness of the situation at hand. Fourth, in the YouTube video there is a series of meanings in it, each image, gesture, expression, audio is significantly different and produce a signified concept of thought and produce the meaning of significance, this is in accordance with the concept of Ferdinand Saussure. The video "COVID-19" shows that the semiotic component can explain the deep meaning of signification in a social campaign video.

\section{REFERENCES}

[1]. Engebretsen, M., \& Kennedy, H. (2020). Data Visualization in Society. New York: Amsterdam University Press.

[2]. Craig, R. T. (2016). Traditions of Communication Theory. The International Encylopedia of Communication Theory and Pholosophy, 1-10.

[3]. Littlejohn, Stephen, W., \& Foss, K. A. (2009). Encyclopedia of Communication Theory. California: Sage Publication.

[4]. Yekini, K. C., Omoteso, K., \& Adegbite, E. (2019). CSR Communication Research: A Theoretical-cumMethodological Perspective From Semiotics. Business \& Society.

[5]. Irawan, E. P. (2019). Semiotic Analysis of the Message Meaning of Corporate Social Responsibility of Aqua Mineral Water "Back to be Pure \#Aqua242" Version, Ramadhan 2018 Edition in Television Media. International Journal of Innovative Science and Research Technology .

[6]. Li, Y. (2017). A semiotic theory of institutionalization. The Academy of Management Review .

[7]. Corndana, R., Johson, K., \& Kenney, M. (2015). A Campaign to Raise Community Awareness of Caregiving . Journal of the American Society on Aging . 
[8]. Sharma, A., Bhosle, A., \& Chaudhary, B. (2012). onsumer Perception and Attitude towards the Visual Elements in Social Campaign Advertisement. IOSR Journal of Business and Management, 06-17.

[9]. Heather L. Gainforth, J. W.-B.-C. Evaluating the ParticipACTION “Think Again” Campaign. 43, 434441.

[10]. Upton, B. (2015). The Aesthetic of Play. London: The MIT Press.

[11]. Barbatsis, G., Kenney, K., \& Smith, K. L. (2005). Handbook of Visual Communication: Theory, Methods, and Media. New Jersey: Lawrence Erlbaum Associate.

[12]. Ying, Y. (2019). On Deconstruction of Linguistic Signs in Rhetorical Activities . Advances in Social Science, Education and Humanities Research, 332.

[13]. Shumin, L. (2019). The Analysis of the Euphemism: From the Semiotic Point of View. Studies in Literature and Language , 19, 22-24.

[14]. ZAHEDI , F. M., \& BANSAL, G. (2011). Cultural Signifiers of Web Site Images. Journal of Management Information Systems, 28, 147-200.

[15]. Epstein, M. (2019). A Philosophy of the Possible: Modalities in Thought and Culture. Boston: Brill Rodopi.

[16]. Mulyana, \& Deddy. (2003). Metode Penelitian Kaulitatif. Bandung: PT Remaja Rosdakarya.

[17]. Patton, \& Quinn, M. (2002). Qualitative Research and Evaluation Methods (3rd edition ed.). California: Sage Publications.

[18]. Sanjaya, W., \& Budimanjaya, A. (2017). Paradigma Baru Mengajar. Jakarta: Kencana.

[19]. Semiawan, C. R. (2010). Metode Penelitian Kualitatif. Jakarta: Grasindo.

[20]. Atkison, J. D. (2017). "The Study of Social Activism." Journey into Social Activism: Qualitative Approaches,. New York: Fordham University Press.

[21]. Parmentier, R. J. (2016). Signs and Society: Further Studies in Semiotic Anthropology. Indianapolis: Indiana University Press About this book.

[22]. Organization, W. H. (2020, 05 10). Emergency Corona Virus Disease (COVID-19) pandemic. From World Health Organization.

[23]. Hirsch, A. T., \& Duval, S. (2013). The global pandemic of peripheral artery disease. The Lancet, 1312-1314.

[24]. Park, H., \& Cho, Y. (2020). Financial Sustainability of Nonprofit Organizations: Determinants of Fundraising Campaigns on Donation Intention. Journal of Industrial Disribution \& Business , III, 1928.

[25]. Song, J.-M., \& Kang, S.-H. (2015). Does Social Distance Always Increase Content Performance in Online Distribution Channels? Journal of Distribution Science, 97-104.

[26]. Lee, J.-M. (2019). A Study on Consumer Value and Corporate Social Responsibility Distribution Activities. Journal of Distribution Science , 17-26. 